\title{
Developing the Agro-Grassland System to Insure Food Security of China
}

\author{
Ruichao Li, Huilong Lin* \\ State Key Laboratory of Grassland Agro-Ecosystems, College of Pastoral Agriculture Science and Technology, \\ Lanzhou University, Lanzhou, China \\ Email: $\underline{\text { linhuilong@|zu.edu.cn }}$
}

Received 14 June 2014

\begin{abstract}
China's food security has always been the top priority in China. As the huge increase of animal food consumption, the current agriculture system in China namely "grain farming", whose major animal feed are grains, seems to meet a great challenge to ensure China's food security in the future. Not only the current situation, but also the production capacity as developing grassland agriculture is analyzed in this paper. The results show that half of provinces don't have enough grain to meet their various needs for grain, and the whole country's potential of grain yield is reaching a limited position. On the other hand, implementing cereal-forage rotation on $20 \%$ of the total arable land and developing high productivity sown pastures on $3 \%$ of the total rangeland areas could create approximately 1.2 times Arable Land Equivalent Unit (ALEU) than ever. So changing the traditional agriculture system into Grassland Agro-Ecosystems is an effective way to insure China's food security. It includes utilization of rangeland rationally, establishment of more sown pasture and implementation of cereal-pasture rotation system, increase livestock production, and use of arable land more efficiently.
\end{abstract}

\section{Keywords}

Food Security, Grassland Agriculture, Arable Land Equivalent Unit, China

\section{Introduction}

Lester Brown has mentioned that China's food problem will threat the food security of the entire world, and China's dependence on massive food imports will be a wake-up call that we are colliding with the earth's capacity to feed us [1]. His results have attracted worldwide attention about food security of China. How to use $7 \%$ of world's cultivated land and $8 \%$ of fresh water to feed China's $22 \%$ of world's population has become a huge problem for world food security and the top priority in China [2] [3].

China's current agriculture system has been defined as "grain farming", with the grain the staple crop and pigs the major livestock, while forage crops are a relatively minor feed source. Because of the high cost of feeding animals in the current system, pigs which have a comparatively high rate of return on fodders, have a signif-

"Corresponding author.

How to cite this paper: Li, R.C. and Lin, H.L. (2014) Developing the Agro-Grassland System to Insure Food Security of China. Journal of Agricultural Chemistry and Environment, 3, 9-15. http://dx.doi.org/10.4236/jacen.2014.33B002 
icant place in the animal products market. Herbivores, which have a comparatively low rate of return on fodders, remain a small proportion of animal production in China.

Nowadays, the concept of food security is evolving into one of nutrition security [4], which means that not only plant food, but also animal food should be taken into consideration to analyze food security problems. But the high expend of animal husbandry in China is inconsistent with the huge increase of animal food consumption, and exert great pressure on the grain production. To solve this new problem, some researchers put forward an idea that developing grassland agriculture in China [5] [6]. Compared to grain farming, grassland agriculture may be described as the art and science of cultivating forage crops, pasture and rangelands for food and fiber production [7]. The American Forage \& Grassland Council defines grassland agriculture as "the proper use of grasses in agriculture", and both grasses and grass-legume mixtures can be used to feed livestock, support wildlife and to maintain land resources in good condition [8]. The effect of grassland agriculture under artificial control of input and output of energy flow, material flow and information flow is to maximize eco-economic benefits [9].

Food has been narrowly defined as grain since food security was been studied in China, so that the food security has been equated to "grain security". Despite the increasing consumption of animal food, almost all researches of food security in China actually focus on grain [2] [10] [11]. So study based on food diversity is urgently needed to evaluate the current situation of food supply and demand and estimate if the current agriculture system is able to guarantee China's food security. Not only the current situation, but also the production capacity when develop grassland agriculture are measured and calculated in the study.

\section{Materials and Methods}

\subsection{Data Acquisition}

The statistics to calculate food consumption and food production of each province in 2011 such as urban and rural population, per capita consumption of different kinds of food were obtained from 2012's National Bureau of Statistics of China [12], as well as the data of grain yield from 1978 to 2011 and the areas of cropland and grassland of different province. The grain consumptions to produce unit animal food in China (Table 1) were from 2002's statistics of the Development Planning Department of Ministry of Agriculture [13]. The concept of Arable Land Equivalent Unit (ALEU) of different land use in different regions is come from Ren and Lin [14] and it will be calculated accordingly.

\subsection{Analyzing the Present Situation of Food Security}

By multiplying per capita food consumption with the population, food grain consumption will be estimated. The quantity of feed grain consumption will be estimated according to multiplying grain consumption that needed to produce a unit animal food (Table 1) by the output of each kind of animal food. Subtracting grain consumption from grain yield, the difference between grain supply and demand will be worked out, only considering the food grain and feed grain as the total grain consumption. All above are done on provincial level, and a distribution map will be drawn in ArcGis9.3 software environment.

Hodrick-Prescott (H-P) filter [15] as a mathematical tool is used to separate the cyclical component from grain yield (EViews 6.0 software) and to reveal the underlying trends in grain yield from 1978 to 2011.

\subsection{Measuring and Calculating the Production Capacity of Grassland Agriculture}

In order to analyze food production capacity, a unified land conversion system namely the Arable Land Equivalent Unit (ALEU) [14] will be introduced in this study, which can place different kinds and quality of land into a common land equivalent for further calculation. The per unit yield of annual rice production in monoculture is regarded as 1 Arable Land Equivalent Unit (ALEU).

Table 1. Grain consumption to produce unit animal food.

\begin{tabular}{cccccc}
\hline & Pork & Beef and mutton & Poultry & Eggs & Milk \\
\hline Grain consumption & 3.5 & 2.5 & 2 & 2.5 & 0.3 \\
\hline
\end{tabular}




\section{Result}

\subsection{Present Situation of Food Security}

Figure 1 shows the gap derived from anomalies between supply and demand of each province in China in 2011. We divided the differences into 4 parts: demand exceeding supply $(<0)$, supply exceeding demand to 3 different degrees $\left(0\right.$ - 500, 500 - 1500, 1500 - 5000. Unit: $10^{4}$ t). There are 10 provinces are in great short of grain in China $(<0)$, which are happen to be the most developed areas such as Beijing, Tianjin, Shanghai, Zhejiang, Fujian, Guangdong and Hainan, and the most underdeveloped areas including Tibet, Qinghai and Guizhou. The reason of this phenomenon occurred is due to the urbanization in developed areas and the poor soil condition in underdeveloped areas. Among these areas, Guangdong province approximately has an as large as 17 million tons gap between grain production and consumption, and becomes the biggest food-deficit province in China. Besides, there are 8 provinces located in the middlewest and southwest which have less than 5 million ton's food surplus. This means that these provinces are actually hard to have remnant considering the other food use and food waste. The 6 provinces with most grain surplus are in the northeast and middle east of China. It is corresponds to the phenomenon of "north to south grain transport" [16].

From whole viewpoint, half of provinces don't have enough grain to meet their various needs for grain; the major grain production areas including Zhejiang, Fujian and Guangdong have become the most grain scarcity provinces; but those provinces in northeast areas with shortage of water and heat has taken the heavy burden to feed China. Such a situation of grain supply and demand will prejudice the China's food security.

Whether could we improve the situation by enhance the yield of grain? The H-P filter has showed that the growth potential of grain yield is limited (Figure 2). According to the result of the H-P filter, the growth potential of grain yield in China has reached a limit. So the wishful thinking which plan to enhance the yield of grain greatly and to improve the grain shortage situation is unpractical.

\subsection{The Production Capacity of Grassland Agriculture}

The grassland agriculture system will include the following main components: in the traditional cropping areas, instead of cereal monoculture, about $20 \%$ of the total arable land area should be used for cereal-forage rotation. In the pastoral areas, high productivity sown pastures should be developed and the area at least should reach $3 \%$ of the total rangeland areas in China. The results the production capacity calculated in this agricultural pattern were listed in Table 2.

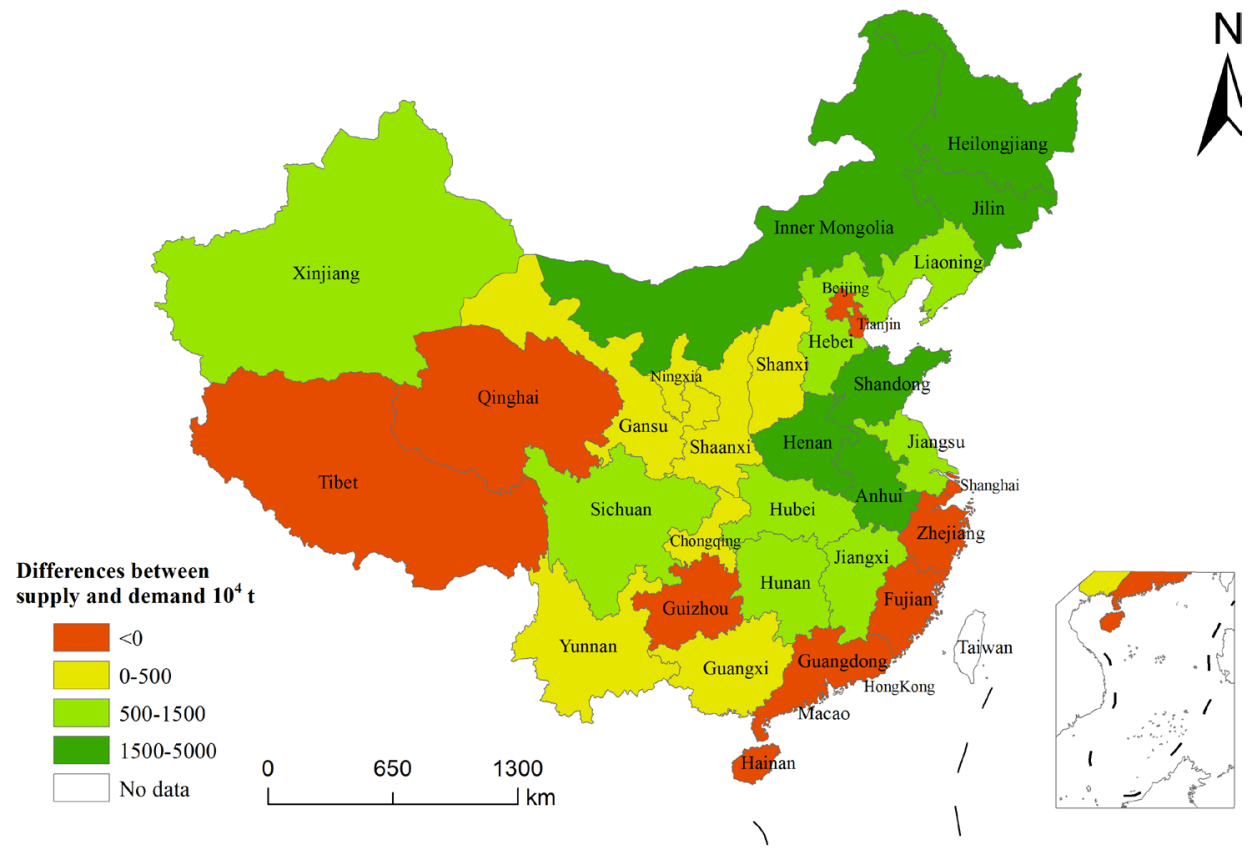

Figure 1. The difference between supply and demand for grain in 2011. 
Table 2. The arable land equivalent unit of grassland agriculture.

\begin{tabular}{|c|c|c|c|c|c|c|c|c|c|}
\hline & \multicolumn{2}{|c|}{ Crop land } & \multicolumn{2}{|c|}{ Natural grassland } & \multicolumn{2}{|c|}{ Cereal-forage rotation } & \multicolumn{2}{|c|}{ Cultivated grassland } & \multirow{2}{*}{$\begin{array}{l}\text { ALEU of } \\
\text { grassland } \\
\text { agriculture }\end{array}$} \\
\hline & ALEU & Area & FEU & Area & ALEU & Area & ALEU & Area & \\
\hline & $\left(\mathrm{hm}^{2} \cdot \mathrm{hm}^{-2}\right)$ & $\left(10^{4} \mathrm{hm}^{2}\right)$ & $\left(\mathrm{hm}^{2} \cdot \mathrm{hm}^{-2}\right)$ & $\left(10^{4} \mathrm{hm}^{2}\right)$ & $\left(\mathrm{hm}^{2} \cdot \mathrm{hm}^{-2}\right)$ & $\left(10^{4} \mathrm{hm}^{2}\right)$ & $\left(\mathrm{hm}^{2} \cdot \mathrm{hm}^{-2}\right)$ & $\left(10^{4} \mathrm{hm}^{2}\right)$ & $\left(10^{4} \mathrm{hm}^{2}\right)$ \\
\hline Beijing & 0.41 & 18.54 & 0.39 & 32.62 & 2.00 & 4.63 & 1.00 & 1.01 & 30.60 \\
\hline Tianjin & 0.41 & 35.29 & 0.39 & 13.13 & 2.00 & 8.82 & 1.00 & 0.41 & 37.64 \\
\hline Hebei & 0.41 & 505.38 & 0.39 & 396.28 & 2.00 & 126.35 & 1.00 & 12.26 & 626.70 \\
\hline Shanxi & 0.41 & 356.46 & 0.39 & 441.54 & 2.00 & 89.12 & 1.00 & 13.66 & 510.24 \\
\hline $\begin{array}{c}\text { Inner } \\
\text { Mongolian }\end{array}$ & 0.41 & 571.78 & 0.30 & 6168.34 & 2.00 & 142.94 & 1.00 & 190.77 & 2561.59 \\
\hline Liaoning & 0.45 & 326.82 & 0.36 & 314.21 & 2.00 & 81.71 & 1.00 & 9.72 & 433.32 \\
\hline Jilin & 0.45 & 442.77 & 0.36 & 424.76 & 2.00 & 110.69 & 1.00 & 13.14 & 586.68 \\
\hline Heilongjiang & 0.45 & 946.41 & 0.36 & 589.92 & 2.00 & 236.60 & 1.00 & 18.24 & 1129.70 \\
\hline Shanghai & 0.59 & 19.52 & 0.76 & 3.62 & 2.83 & 4.88 & 1.00 & 0.11 & 28.19 \\
\hline Jiangsu & 0.59 & 381.10 & 0.76 & 31.59 & 2.83 & 95.28 & 1.00 & 0.98 & 519.47 \\
\hline Zhejiang & 0.59 & 153.67 & 0.76 & 201.29 & 2.83 & 38.42 & 1.00 & 6.23 & 358.60 \\
\hline Anhui & 0.59 & 458.42 & 0.76 & 144.06 & 2.83 & 114.60 & 1.00 & 4.46 & 708.74 \\
\hline Fujian & 0.95 & 106.41 & 0.76 & 189.83 & 2.83 & 26.60 & 1.00 & 5.87 & 326.52 \\
\hline Jiangxi & 0.59 & 226.17 & 0.76 & 373.21 & 2.83 & 56.54 & 1.00 & 11.54 & 588.64 \\
\hline Shandong & 0.59 & 601.22 & 0.39 & 128.93 & 2.00 & 150.31 & 1.00 & 3.99 & 709.60 \\
\hline Henan & 0.59 & 634.11 & 0.39 & 392.20 & 2.00 & 158.53 & 1.00 & 12.13 & 856.27 \\
\hline Hubei & 0.59 & 373.13 & 0.74 & 491.94 & 3.90 & 93.28 & 1.00 & 15.21 & 963.19 \\
\hline Hunan & 0.59 & 303.15 & 0.74 & 549.63 & 3.90 & 75.79 & 1.00 & 17.00 & 898.16 \\
\hline Guangdong & 0.95 & 226.46 & 0.76 & 259.69 & 2.83 & 56.61 & 1.00 & 8.03 & 580.75 \\
\hline Guangxi & 0.95 & 337.40 & 0.74 & 630.53 & 3.90 & 84.35 & 1.00 & 19.50 & 1135.59 \\
\hline Hainan & 0.95 & 58.20 & 0.76 & 81.80 & 2.83 & 14.55 & 1.00 & 2.53 & 161.16 \\
\hline Chongqing & 0.59 & 178.87 & 0.74 & 181.12 & 3.90 & 44.72 & 1.00 & 5.60 & 419.57 \\
\hline Sichuan & 0.59 & 475.79 & 0.74 & 1722.05 & 3.90 & 118.95 & 1.00 & 53.26 & 2072.19 \\
\hline Guizhou & 0.59 & 358.82 & 0.74 & 364.69 & 3.90 & 89.71 & 1.00 & 11.28 & 842.71 \\
\hline Yunnan & 0.59 & 485.77 & 0.74 & 1156.78 & 3.90 & 121.44 & 1.00 & 35.78 & 1652.02 \\
\hline Tibet & 0.59 & 28.93 & 0.37 & 6872.14 & 2.00 & 7.23 & 1.00 & 212.54 & 2786.76 \\
\hline Shaanxi & 0.33 & 324.02 & 0.39 & 421.87 & 2.00 & 81.01 & 1.00 & 13.05 & 446.52 \\
\hline Gansu & 0.33 & 372.70 & 0.37 & 1558.95 & 2.00 & 93.18 & 1.00 & 48.21 & 934.37 \\
\hline Qinghai & 0.33 & 43.42 & 0.37 & 3058.47 & 2.00 & 10.85 & 1.00 & 94.59 & 1262.26 \\
\hline Ningxia & 0.33 & 88.57 & 0.30 & 254.68 & 2.00 & 22.14 & 1.00 & 7.88 & 157.79 \\
\hline Xinjiang & 0.33 & 329.97 & 0.15 & 4452.51 & 2.00 & 82.49 & 1.00 & 137.71 & 1079.46 \\
\hline
\end{tabular}




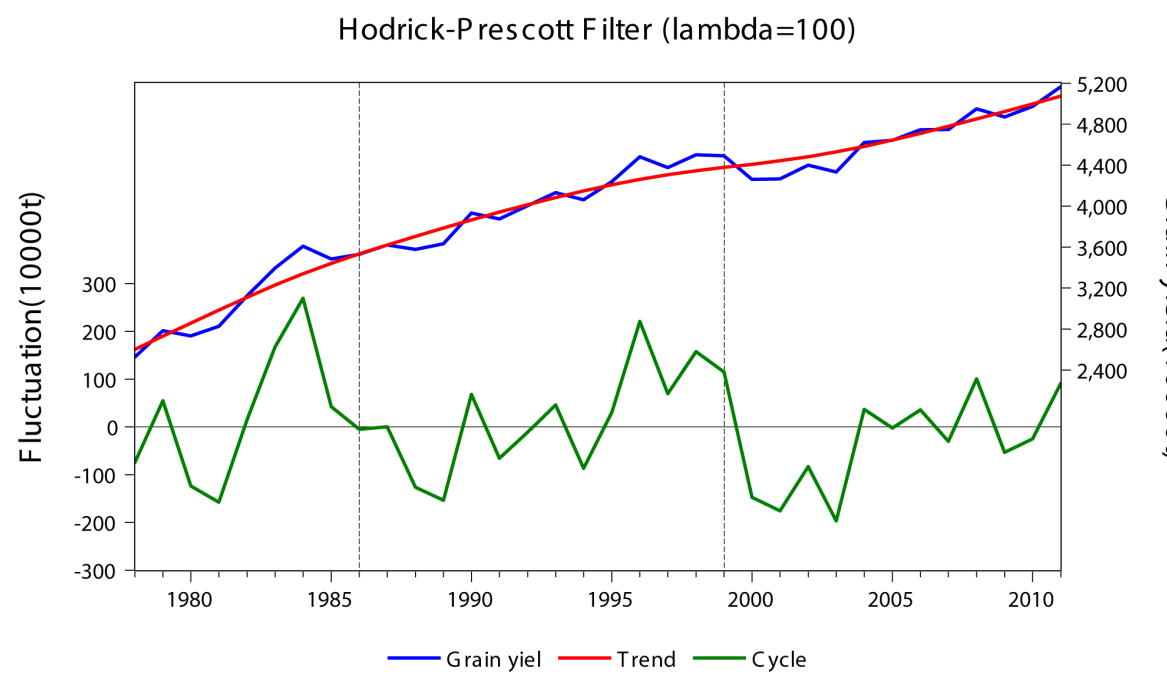

$\frac{0}{2}$
$\frac{0}{5}$
․
을
응
을

Figure 2. H-P filter analysis of grain yield in China from 1978 to 2011.

In the part of crop land, if the cereal-forage rotation is put in force, it would increase 51 million hm² ALEU in China, and would be as twice as it was in the past. Because of the high ALEU by cereal-forage rotation in the southwest region $\left(3.9 \mathrm{hm}^{2} / \mathrm{hm}^{2}\right)$, implementation of grassland agriculture among traditional cropping areas would increase ALEU about 51\%, which is more than other regions. In grassland regions, the high productivity cultivated grassland established could increase approximately 6 million $\mathrm{hm}^{2}$ ALEU. Cultivated grassland built in the Tibet, Qinghai and Inner Mongolian which are full of grassland resource could increase 3.3 more ALEU which is $55 \%$ of the country's whole increased ALEU. Totally, the potential lands' production capacity of grassland agriculture is to be about 254 million $\mathrm{hm}^{2}$ ALEU. The land output ability in grassland agriculture is to be 1.3 times than the traditional "grain farming", meanwhile Jiangsu province will reached 1.7 times.

\section{Discussion}

As China's food security has some new problems such as the limited capacity for grain production, competitive demands for grain with human and animal foods, unreasonable utilization in water resource [17] and the vulnerability to global climate change. To ensure China's food security in the future under China's current agriculture system is really a great challenge not only for Chinese central government but for the whole world. So the current agriculture system was found to be outdated [6], and as is analyzed above, grassland agriculture would be an alternative.

In facing up to the continuing increase of animal food demand, grassland agriculture has some advantages. Firstly, it can differentiate food consumed by human beings and by livestock. That is because of the ruminants which are the main kind of animal in grassland agriculture. Compared with grain-fed animals such as pig and poultry, ruminants can increase the grain input-output ratio by lower inputs of grains and higher inputs of grass [18], thereby saving feed grain and reducing the pressure on food security. Besides, grassland agriculture could provide a large number of high-quality animal foods. A lot of practices have proved that use high-quality legume-grass meal to feed chickens, pigs, cattle, sheep and other livestock can boost output of live stocks by $10 \%$ to $17 \%$ [19].

There exists an abundant grassland resource in China. The area of available grassland is almost 2.7 times than that of the cropland. To develop grassland agriculture in different regions could take full advantage of the nutrition efficiency in agriculture and can, optimize food structure, and solve different problems of food security in different areas. The water and heat condition in south China is the best of the whole country, and is fit well to develop grassland agriculture. To implement grassland agriculture here will enhance the food output in southern China and change the situation of grain shortage. The west of China has been the country's traditional pasturing areas which nowadays meet the grain shortage problem because of the too much use of feed grain. The grassland of this region takes about $75 \%$ of the total grassland area in China. So the west region has a large potential to develop grassland agriculture. Using grass instead of grain to feed animals could bring about a larger output of 
animal food to the country and will solve its own food problems. The northeast and the middle east of China are the main grain production regions. Monoculture of grain will cause excessive use of land and lead to non-point source pollution and soil fertility decline. Developing grassland agriculture here will improve the soil condition and solve the pollution problem [20].

To take full advantage of these Grassland Agro-Ecosystems will avoid wasting and leaving unused. For grassland agriculture to emerge and fully develop, changes in government policies will be needed [21].

1) Educate future students, producers, and the general public about the multifunctional nature of grasslands and the services they provide;

2) Increase public research funding for grass and forage production and utilization;

3) Minimize price support programs that reward cereal monoculture and increase subsidies on grass and grazing.

\section{Acknowledgements}

The research was supported by the key consultative project "Ecological security of grassland and food security in China” by Chinese Academy of Engineering (2012-ZD-7) and Program for Changjiang Scholars and Innovative Research Team in University (IRT13019).

\section{References}

[1] Brown, L.R. (1995) Who Will Feed China?: Wake-Up Call for a Small Planet. WW Norton \& Company, New York.

[2] Wong, J. and Huang, Y.J. (2012) China’s Food Security and Its Global Implications. China: An International Journal, 10, 113-124.

[3] Sun, C.Z., Liu, Y.Y., Chen, L.X. and Zhang, L. (2010) Analysis on Virtual Water Flows Pattern Embedded in China's Crops Trade and Its Causes-Added Discussion on the Applicability of "Virtual Water Strategy" in China. China Soft Science, 7, 36-44. (in Chinese)

[4] CFS (2013) Food Security Indicators. http://www.fao.org/cfs/en/

[5] Ren, J.Z., Nan, Z.B. and Lin, H.L. (2005) Taking the Grassland Agro-System to Insure Food Security. Acta Prataculturae Sinica, 14, 1-10. (in Chinese)

[6] Ren, J.Z., Lin, H.L. and Hou, X.Y. (2007) Developing the Agro-Grassland System to Insure Food Security of China. Scientia Agricultura Sinica, 40, 614-621. (in Chinese)

[7] Barnes, R.F. (2006) Grassland Agriculture-Serving Mankind. Rangelands Archives, 4, 61-62.

[8] National Forage \& Grasslands Curriculum (2013) Define Grassland Agriculture, Discuss a Typical Grassland Ecosystem. http://forages.oregonstate.edu/nfgc/eo/onlineforagecurriculum/instructormaterials/availabletopics/introduction/definition

[9] Tang, J. and Lin, H.L. (2013) Analysis of Characteristics of the Circular Economy of Grassland Farming. Acta Prataculturae Sinica, 22, 167-175. (in Chinese)

[10] Fan, M.S., Shen, J.B., Yuan, L.X., Jiang, R.F., Chen, X.P., Davies, W.J. and Zhang, F.S. (2012) Improving Crop Productivity and Resource Use Efficiency to Ensure Food Security and Environmental Quality in China. Journal of Experimental Botany, 63, 13-24. http://dx.doi.org/10.1093/jxb/err248

[11] Lu, Q.S., Xu, B., Liang, F.Y., Gao, Z.Q. and Ning, J.C. (2013) Influences of the Grain-for-Green Project on Grain Security in Southern China. Ecological Indicators, 34, 616-622. http://dx.doi.org/10.1016/j.ecolind.2013.06.026

[12] National Bureau of Statistics of China. http://www.stats.gov.cn/tjsj/ndsj/2012/indexch.htm

[13] The Development Planning Department of Ministry of Agriculture (2002) China Agricultural Outlook at the Beginning of New Century. China Agriculture Press, Beijing. (in Chinese)

[14] Ren, J.Z. and Lin, H.L. (2006) Arable Land Equivalent Unit and Potential Food Productivity of Land Resources in China. Acta Prataculturae Sinica, 15, 1-10. (in Chinese)

[15] Hodrick, R.J. and Prescott, E.C. (1997) Postwar US Business Cycles: An Empirical Investigation. Journal of Money, Credit, and Banking, 1-16. http://dx.doi.org/10.2307/2953682

[16] Huang, Q. (2010) Changes of Food Supply-Demand Pattern and Strategic Allocation of Sunlight, Warmth and Water Resources in China. Acta Prataculturae Sinica, 19. (in Chinese)

[17] Lin, H.L., Li, R.C., Jin, C.Y., Wang, C., Wei, M.H. and Ren, J.Z. (2014) China’s New Problems of Food Security Revealed by the Food Equivalent Unit. Frontiers of Agricultural Science and Engineering, 1, 69-76.

[18] O’Mara, F.P. (2012) The Role of Grasslands in Food Security and Climate Change. Annals of Botany, 110, $1263-1270$. 
http://dx.doi.org/10.1093/aob/mcs209

[19] Li, Y.T. (2009) Ways to Ensure Food Security Strategy in China—Developing Forage Protein Feed and Reducing Grain for Feeding Stuff. Prata-Cultural Science, 26, 1-4. (in Chinese)

[20] Li, Y.Y. and Zhang, G.R. (2000) The Study on Benefits of Grassland Agriculture. Journal of Guangxi Agriculture and Biological Science, 19, 59-63. (in Chinese)

[21] Wedin, W.F. and Fales, S.L. (2009) Grassland: Quietness and Strength for a New American Agriculture: ASA-CSSASSSA. 